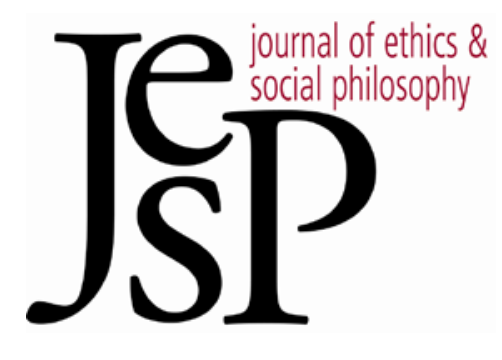

\title{
An Actual-Sequence Theory of Promotion
}

\author{
By D. Justin CoATES
}

JOURNAL OF ETHICS \& SOCIAL PHILOSOPHY

Discussion Note | JANUARY 2014 URL: WWW.JESP.ORG COPYRIGHT @ D. JUSTIN COATES 2014 


\title{
An Actual-Sequence Theory of Promotion \\ D. Justin Coates
}

\begin{abstract}
1 CCORDING TO HUMEAN THEORIES, the existence of an A agent's reason $R$ to $\mathrm{x}$ will ultimately depend on whether $\mathrm{x}$-ing on the 1 basis of $R$ will promote the object of some particular motivational state (e.g., a desire). Thus, the notion of promotion plays a vitally important role in such theories. But what is it to promote the object of one of these motivational states? Plausibly, it has something to do with making the state of affairs picked out by the object of a particular motivational state more likely or more probable. On this probabilistic view, $S$ promotes the object of some motivational state by making it more likely that the object of that state obtains. But a question remains: what are we comparing when we say that $\mathrm{x}$ ing makes the object of a desire more likely (rather than just likely simpliciter)? That is, what is the relevant comparison class?

In an effort to clarify the promotion relationship, I consider a recent critique of probabilistic analyses of the promotion relationship. Jeff Behrends and Joshua DiPaolo ("Finlay and Schroeder on Promoting a Desire" Journal of Ethics and Social Philosophy, December 2011: 1-7) argue that accounts of promotion due to Stephen Finlay ("The Reasons that Matter" Australasian Journal of Philosophy, 84.1 (2006): 1-20) and Mark Schroeder (Slaves of the Passions, Oxford: Oxford University Press, (2007)) are inadequate. After considering Behrends and DiPaolo's criticisms of these probabilistic analyses of promotion, I suggest an alternative analysis of promotion according to which an action promotes the object of a motivational state if and only if by performing that action the agent renders the object of the motivational state more likely to obtain relative to its antecedent intrinsic likelihood of obtaining. And this probabilistic analysis, I claim, not only captures the intuitive appeal of probabilistic analyses more generally, but also is not subject to Behrends and DiPaolo's counterexamples.
\end{abstract}

1.

To begin, consider Behrends and DiPaolo's rendering of Stephen Finlay's analysis of the promotion relationship:

Promotion $_{1}$

For some agent $\mathrm{X}$, desire $\mathrm{D}$, and action $\mathrm{A}, \mathrm{A}$ promotes $\mathrm{p}$ - the object of $\mathrm{D}$ - iff X's doing A renders $\mathrm{p}$ more likely than it would have been had $\mathrm{X}$ not done A (Behrends and DiPaolo 2011: 1).

As a first pass, this seems plausible. It is, after all, natural to think that I promote the object of my desire to have a drink by bringing the cup to my 
lips because, by bringing the cup to my lips, I make it more likely that the object of my desire will obtain than it would have had I not brought the cup to my lips. However, Behrends and DiPaolo offer a counterexample to Promotion $_{1}$. Consider the following case:

Buttons

Debbie has some desire. There are three buttons in front of her. If she pushes either Button A or Button B, her desire is guaranteed to be fulfilled. If she pushes Button $C$, her desire will not be fulfilled. Debbie in fact pushes A. Had she not pushed A, though, she would have pushed B instead (Behrends and DiPaolo 2011: 2).

In this case, if we accept Promotion ${ }_{1}$, then it seems as if Debbie does not promote her desire by pressing Button $A$, since, had she refrained from pressing Button A, she would have pressed Button B, which would have made it no less likely that the object of her desire obtain. But this is incredible! How could pressing Button A not count as promoting her desire since Debbie guarantees the satisfaction of her desire? And if guaranteeing the satisfaction of a desire does not count as promoting that desire, what would?

But Behrends and DiPaolo offer a further reason for thinking that

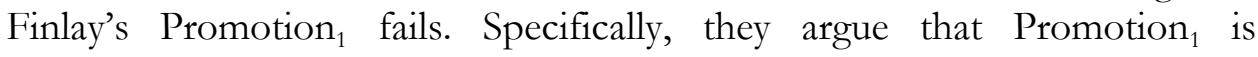
inconsistent with a plausible account of instrumental rationality. According to this account - Instrumental Reason - "for X to have an instrumental reason to $\mathrm{A}$ is for there to be some $\mathrm{p}$ such that $\mathrm{X}$ has a desire the object of which is $\mathrm{p}$, and for there to be some fact that is part of what explains why X's doing A promotes p" (Behrends and DiPaolo 2011: 3). Because Promotion entails that Debbie does not promote her desire by selecting Button A, Instrumental Reason would entail that she had no reason to press Button $\mathrm{A}$ in Buttons. However, this is false, since given her desire she clearly has more reason to press Button A than to press Button $\mathrm{C}$, and if she has more reason, then that

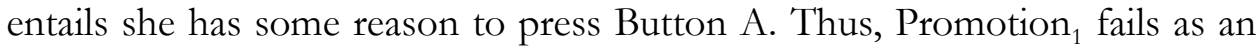
account of the promotion relationship since it is inconsistent with Instrumental Reason.

2.

Having offered us some reason to reject Promotion $_{1}$, Behrends and DiPaolo turn their attention to Mark Schroeder's analysis of promotion, which they state as:

Promotion $_{2}$

For some agent X, desire D, and action A, A promotes $\mathrm{p}$ - the object of D - iff X's doing $\mathrm{A}$ renders $\mathrm{p}$ more likely than it would have been had $\mathrm{X}$ done nothing (Behrends and DiPaolo 2011: 4).

As was the case with Promotion $_{1}$, Schroeder's Promotion ${ }_{2}$ seems initially

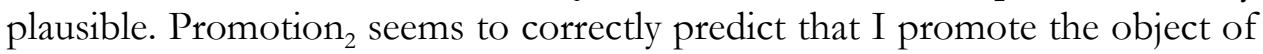


my desire to watch the game by turning on the TV: by turning on the TV, I make it more likely that I will get to see the game than I would have been had I done nothing.

But again, Behrends and DiPaolo offer us two reasons to doubt its adequacy. ${ }^{1}$ First, they offer a variant of Buttons.

Buttons 2

Julie has some desire. There is one button in front of her. She knows that if she pushes the button, her desire is guaranteed to be fulfilled. However, unbeknownst to Julie, if she does not push the button, Black will ensure that her desire is fulfilled (Behrends and DiPaolo 2001: 4).

Once we consider Buttons 2, we'll see that if Promotion ${ }_{2}$ is true, then Julie will not promote her desire by pressing the button. And again, this is surprising since, by pressing the button, she guarantees the satisfaction of the desire.

At this point, Behrends and DiPaolo are just getting started, since as was the case for Promotion ${ }_{1}$, there is also a deeper problem for Promotion ${ }_{2}$.

Do Nothing

At $t_{1}$ Austin forms the desire that $p$ be the case at $t_{3}$. Black has arranged things such that if Austin does nothing at $t_{2}, p$ will be the case at $t_{3}$; Black has further arranged things such that any other behavior at $t_{2}$ on Austin's part will result in not- $\mathrm{p}$ (Behrends and DiPaolo 2011: 4).

In this case, Behrends and DiPaolo rightly note that it seems as if Austin has

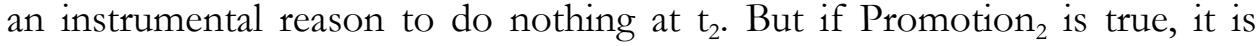
unclear how any agent could have a reason to do nothing since doing nothing can never render a state of affairs more likely to obtain than if the agent were to do nothing. After all, it is obviously the case that doing nothing makes it exactly as likely that the object of some motivational state obtains as does doing nothing. For any two instances of doing nothing are tokens of the same activity (or omission), and so relate to the likelihood of some state of affairs obtaining in exactly the same way. Accordingly, doing nothing can never render $\mathrm{p}$ more likely than doing nothing.

Therefore, it seems that on Promotion $_{2}$, doing nothing can never promote a desire. Of course, doing nothing can promote desires, since the best explanation of why Austin has an instrumental reason to do nothing at $\mathrm{t}_{2}$ is that, by doing nothing, he will promote the object of his desire that $\mathrm{p}$. Therefore, we should reject Schroeder's Promotion ${ }_{2}$ as an adequate analysis of the promotion relationship.

${ }^{1}$ For another objection to Schroeder's account of the promotion relationship, see Daan Evers (2009) “Humean Agent-Neutral Reasons?” Philosophical Explorations 12(1): 55-67. 
3.

But now that we have rejected Finlay's Promotion P $_{1}$ and Schroeder's Promotion $_{2}$, where should we look for an adequate account of the promotion relationship? Behrends and DiPaolo conclude their discussion with some suggestions. Specifically they claim that:

[These counterexamples] may even suggest that promotion is best thought of nonprobabilistically. For, one might think, the central motivation for offering a probabilistic account of promotion is that, prima facie, promotion seems to require an increase in probability. Once serious doubt has been cast upon that position, though, probabilistic accounts might turn out to be unmotivated (Behrends and DiPaolo 2011: 5).

But I think this is too quick. Plausibly, Behrends and DiPaolo have given us reason to doubt the adequacy of Promotion Pand Promotion $_{2}$. However, the problem, as I see it, is not that these analyses of the promotion relationship are probabilistic; rather it is that they are alternate-sequence analyses. Note

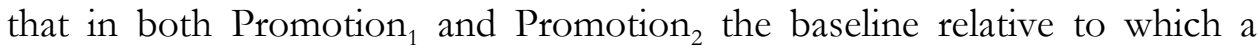
particular course of action is compared is what happens if the agent does otherwise (in the case of Finlay's Promotion ) $_{1}$ or what happens if the agent does nothing (in the case of Schroeder's Promotion P $_{2}$.

But plausibly, whether A-ing promotes $\mathrm{p}$ - the object of $\mathrm{D}-$ is not a matter of what happens in any alternative sequences. So the relevant comparison class should not invoke such alternatives. Instead, it seems that whether A-ing promotes $\mathrm{p}$ is strictly a matter of the actual causal sequence. Indeed, the very case that Behrends and DiPaolo use to undermine Schroeder's Promotion ${ }_{2}$ is one that is relevantly similar to Frankfurt-style cases. 2 And the "moral" of the Frankfurt cases is that the alternative sequence - and in particular, what the agent does in some alternative sequence - is irrelevant to the question of whether she is morally responsible for her action. ${ }^{3}$ Of course, whether Frankfurt cases succeed in showing that the alternative sequence is irrelevant to moral responsibility is quite controversial. But it seems to me that Behrends and DiPaolo's Do Nothing actually gives us good reason to doubt that alternative-sequence probabilistic accounts of promotion are adequate. However, this does not mean that all probabilistic accounts of promotion need to be put out to pasture, as Behrends and DiPaolo suggest, only that alternative-sequence probabilistic accounts should be rejected.

2 Harry Frankfurt (1969) “Alternate Possibilities and Moral Responsibility," Journal of Philosophy 66(23): 829-39. Though Behrends and DiPaolo also note the structural similarities between Buttons 2 and Frankfurt-style cases, I do not think that they fully appreciate the import of these cases (and how they might be relevant to a theory of promotion).

${ }^{3}$ For more on the "moral" of the Frankfurt cases, see John Martin Fischer (2010) "The Frankfurt Cases: The Moral of the Stories," Philosophical Review 119: 315-36. 
With this in mind, I offer a third probabilistic account of the promotion relation.

\footnotetext{
Promotion $_{3}$

For some agent X, desire D, and action A, A promotes $\mathrm{p}$ - the object of D - iff X's doing $\mathrm{A}$ renders $\mathrm{p}$ more likely relative to the antecedent intrinsic likelihood of $\mathrm{p}$ obtaining.
}

On Promotion 3 , it is not what happens in some alternative sequence that determines whether a particular course of action promotes the object of an agent's motivational state. Instead, it is whether the likelihood of $\mathrm{p}$ obtaining is greater after the agent acts than it was before she acted. To illustrate, I will begin with a simple case. Take my desire to finish a book manuscript. If I work on my manuscript for at least eight hours a day, then I promote the object of my desire - viz., that I be finished with my book. And Promotion gives us a plausible explanation of this. After all, the antecedent intrinsic likelihood of my manuscript being finished without at least eight hours per day of work is much lower than is the likelihood of my manuscript being finished with at least eight hours per day of work.

Of course, even Promotion P $_{1}$ and Promotion $_{2}$ can explain this. But Promotion $_{3}$ is better than these alternative-sequence analyses because it can also explain why Debbie and Julie promote their desires in Buttons and Buttons 2. Consequently, Promotion 3 can explain why Debbie and Austin have instrumental reasons in Instrumental Reason and Do Nothing. To see this, notice that, in Buttons, because it is possible (however improbable) that Debbie will push $\mathrm{C}$, the fact that she actually pushes $\mathrm{A}$ - an action that guarantees that the object of her desire is satisfied - will promote the object of her desire if Promotion $_{3}$ is true. For in the actual sequence, the antecedent intrinsic likelihood that Debbie satisfies the object of her desire is raised from some probability less than 1.0 to 1.0 by her action. Of course, it is true that Debbie would have pushed $\mathrm{B}$ if she had not pushed $\mathrm{A}$ and that $\mathrm{B}$ also would have satisfied the object of her desire. But this fact (that is made true in virtue of the nearest set of possible worlds) is irrelevant to whether the probability of the object of her desire being satisfied is made more likely by her pressing A relative to its antecedent intrinsic likelihood. After all, though it is true that, in the nearest set of worlds in which Debbie does not press A she does press $\mathrm{B}$, it does not follow from this that there are no worlds in which she presses C. Moreover, nothing about the state of affairs before Debbie's decision to push A strictly entails that Debbie will choose anything (after all, it is possible that the world ends before she is able to make a decision). Thus, it seems overdetermined that the antecedent intrinsic likelihood that Debbie will satisfy the object of her desire must be less than 1.0. And given Promotion ${ }_{3}$, it seems clear that Debbie does, in fact, have an instrumental reason to push A, since, by so doing, she will raise the probability that she will satisfy the object of her desire to 1.0, which (quite obviously) is greater than the 
antecedent intrinsic probability that Debbie's desire will be satisfied. ${ }^{4}$ Consequently, because Buttons does not show Promotion $_{3}$ to entail that Debbie does not promote the object of her desire even though she

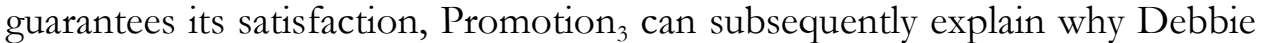
has an instrumental reason to press A. And this shows that Promotion ${ }_{3}$ is

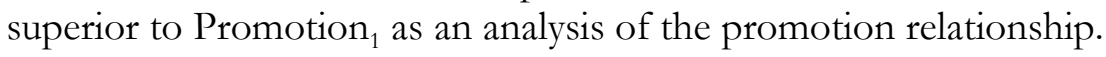

Likewise, with the help of Behrends and DiPaolo's cases, we can see why Promotion improves on Promotion $_{2}$. Unlike Promotion ${ }_{2}$, Promotion 3 predicts that Julie promotes her desire in Buttons 2 and that Austin has an instrumental reason to do nothing in Do Nothing, which requires that he can promote the object of his desire by doing nothing. After all, while Buttons 2 is plausibly a counterexample to Promotion ${ }_{2}$, it gives us no reason to doubt Promotion $_{3}$. Consider that Black will ensure that Julie's desire is fulfilled only if Julie refrains from pushing the button. And because we are imagining that Julie does in fact push the button, it follows that Black plays no role in the actual sequence; he is merely a counterfactual promoter. ${ }^{5}$ But again, on Promotion $_{3}$, alternative sequences are irrelevant to whether a particular course of action promotes the object of an agent's desire. Rather, promotion is simply a matter of whether the likelihood that the agent will satisfy the object of her desire by X-ing is greater than the antecedent intrinsic likelihood that she will satisfy the object of her desire.

Now, you might worry that, even here, given Black's presence, the antecedent probability that the object of her desire is satisfied is 1 . After all, if Julie presses the button then she guarantees that the object of her desire will be satisfied, and if she does not push the button then Black ensures that the object of her desire will be satisfied. Since these seem to be the only options, it might seem that the probability that her desire is satisfied is 1 and that nothing she can do can increase the likelihood of something that has a probability of obtaining of 1 .

But this is not quite right, since probabilities depend on more factors than what happens in the nearby possible worlds that determine the truth of counterfactuals - counterfactuals such as what Black would do if Julie were to refrain from pressing the button. Moreover, intrinsic probabilities of the sort that are relevant to Promotion $_{3}$ do not depend on extrinsic features of the actual sequence (like the presence of Black). To see this, consider a fair six-sided die that is rolled. Making some standard assumptions, the antecedent intrinsic probability that a 3 will come up is roughly .166. But this is true even if God always miraculously kept the die rolling until it came up 3 (such that 1, 2, 4, 5 or 6 was never rolled). No doubt, God's presence guarantees that the die will come up 3 , such that if we rolled it $n$ times, it would come up $3 n$ times. But again, this does not entail that the antecedent

${ }^{4} \mathrm{I}$ am grateful to an anonymous referee for encouraging me to develop this point in more detail.

${ }_{5}^{5}$ Compare this to Black's role as a counterfactual intervener in Frankfurt-style cases. 
intrinsic probability of the die coming up 3 is 1 , since the intrinsic probability of some outcome is presumably determined by the intrinsic properties of the event itself, and God's miraculous involvement in the outcome is not an antecedent intrinsic property of rolling a die.

The same will be true for the antecedent intrinsic likelihood that the object of Julie's desire will be satisfied. Although, in the case in which she knows that pressing the button will guarantee that her desire will be satisfied, this by itself does not entail that her desire will be satisfied, since it does not entail that she will press the button. For example, if the desire in question is relatively insignificant, it would not be incredible that she would forgo pushing the button. Or if Julie thinks that pressing the button will satisfy a bad desire, she might similarly refrain. In any case, this shows that, given the range of options open to her, the antecedent intrinsic probability that she will satisfy the object of her desire is something less than 1 . So, in those cases in which she does push the button, she raises the likelihood of her desire being satisfied relative to this baseline (i.e., the antecedent intrinsic probability). Consequently, in such cases, she promotes her desire, and this shows Promotion $_{3}$ to be adequate in a way that Promotion ${ }_{2}$ is not. Probabilistic analyses are thus vindicated. ${ }^{6}$

D. Justin Coates

University of Houston

Department of Philosophy

djcoates@central.uh.edu

${ }^{6}$ For helpful comments on earlier drafts of this paper, I would like to thank John Martin Fischer, Michael Nelson and an anonymous referee. 